\title{
PUBLICIDADE PERSUASIVA. REVISÃO BIBLIOGRÁFICA
}

\author{
Santos, J. \\ Aluna(o) do 3aano de Psicologia da Universidade Autónoma de Lisboa \\ Joel_santos20@hotmail.com \\ Nascimento, A. \\ Aluna(0) do 3ano de Psicologia da Universidade Autónoma de Lisboa \\ Peixoto, C. \\ Aluna(0) do 3aano de Psicologia da Universidade Autónoma de Lisboa \\ Assunção, M. \\ Aluna(0) do 3ºno de Psicologia dả Universidade Autónoma de Lisboa \\ Lapa Esteves, M. \\ Docente da Universidade Autónoma de Lisboa (UAL). Portugal. \\ mlesteves@autonoma.pt \\ Magalhães, J. \\ Docente da Universidade Autónoma de Lisboa (UAL). Portugal. \\ jose.magalhaes@ine.pt
}

Recepción Artículo: 3 febrero 2020 Admisión Evaluación: 4 marzo 2020

Informe Evaluador 1: 10 m 2020

Informe Evaluador 2: 15 marzo 2020

Aprobación Publicación: 20 abril 2020

\section{RESUMO}

0 presente trabalho dá enfase a uma exploração centrada na persuasão da comunicação, tal como os meios a que se podem estender. Numa busca de revisão bibliográfica com a maior atualidade possível, foi verificado um enfoque na parte retórica que advém do célebre Aristóteles (384-322 a.c.). Quis o filósofo grego durante o período clássico grego que compreendessem um modelo de comunicação que ainda hoje é utilizado. Ainda que hoje a comunicação seja mais mediática, através dos media e por sua vez na publicidade, promove-se a analise dos discursos, técnicas de argumentação e figuras de estilo, de modo, a ser transmitida a informação relevante e a adotar comportamentos adequados. Atualmente há uma evolução na medida em que a retórica moderna predomina, existindo uma maior sofisticação. É de salientar que a persuasão ainda tem limitações devido às crenças dos sujeitos. Diz-nos a literatura de que as causas psicossociológicas da publicidade ocorrem por meio do conformismo e imitação social, devido também à cultura em que nos inserimos e muitas vezes ainda de um modo inconsciente.

Palavras-chave: comunicação; persuasão; psicossociologia

\section{ABSTRACT}

Persuasive. Review adverstising. The present work emphasizes an exploration focused on the persuasion of communication, as well as the means to which they can be extended. In a search for a bibliographic review 
with the greatest possible timeliness, a focus was found on the rhetorical part that comes from the famous Aristotle (384-322 BC). The Greek philosopher wanted during the classical Greek period to understand a model of communication that is still used today. Even though communication today is more media, through the media and in turn in advertising, the analysis of speeches, argumentation techniques and figures of style is promoted, in order to transmit relevant information and adopt appropriate behaviors. Currently there is an evolution as modern rhetoric predominates, with greater sophistication. It should be noted that persuasion still has limitations due to the subjects' beliefs. The literature tells us that the psychosociological causes of advertising occur due to conformism and social imitation, also due to the culture in which we operate and often even unconsciously.

Keywords: persuasion; communication; psychosociology

\section{INTRODUÇÃo}

Persuadir, segundo Citelli (1993) citado por Leite \& Barbosa, é a arte da retórica, na forma como se colocam as palavras. Leite \& Batista (2009), refere que a etimologia da palavra persuasão vem do latim, persuadere que significa convencer completamente. Para Kulcinski (2014), persuadir é levar uma pessoa a crer em alguma coisa.

Quando se fala em persuasão, fala-se em retórica. Fala-se da importância da eloquência para os gregos e do embelezamento do discurso de maneira tal que convencesse a assembleia (Sousa, 2001; Citelli, 2002).

No modelo de comunicação triangular proposto por Aristóteles foi acrescentado mais um elemento, os meios. E desta forma dá-se a passagem da retórica clássica para a retórica moderna, em que as agências de comunicação tornam-se relevantes (Fidalgo, 2010).

Os meios desafiaram os oradores de tal forma que 0 ato de persuadir tornou-se uma profissão nos dias de hoje (Mateus, 2018).

Os textos publicitários têm a capacidade de gerar grande impacto devido à forma como são estruturados, e mais ainda quando não cumprem as normas predeterminadas pela sociedade levando à indignação ou reflexão. Pode-se até dizer persuasivo por excelência, por levar um indivíduo à tomada de decisão. Esse é um dos principais papéis da persuasão (Citelli, 2002).

Este trabalho tem por objetivo a revisão de literatura atualizada da publicidade persuasiva. 0 seu percurso histórico e conceito de persuasão e retórica, bem como a passagem da retórica clássica até à retórica moderna e mediatizada. Será abordado segundo Citelli (2002) as técnicas de publicidade persuasiva, de que maneira os textos persuasivos podem influenciar a publicidade e apresentar o exemplo de um bom slogan e as suas características.

Por fim, serão apresentadas as causas psicossociológicas da publicidade contemporânea, segundo Mateus (2011) designadas por conformismo e imitação social.

\section{DESENVOLVIMENTO}

\section{Conceito de Persuasão}

Segundo Leite \& Batista (2009), a etimologia da palavra persuasão vem de persuadere (per+suadere) que significa convencer completamente. Ou seja, podemos definir como a ação de dar informações e apresentar argumentos que sejam válidos ou não e que levem o indivíduo a adotar ou não determinados comportamentos.

É a arte da retórica, na forma como se coloca as palavras e que tem o objetivo de convencer o recetor de determinada verdade (Citelli, 1993 as cited in Leite e Batista, 2009).

Persuadir é levar uma pessoa a crer em alguma coisa (Kulcinski, 2014).

Para se persuadir o individuo depende dos conhecimentos que o mesmo tem sobre determinado tema. Uma vez que cognição humana abarca um conjunto de crenças geradas pela própria pessoa mediante as conclusões que 0 mesmo faz do que observa, pode-se dizer que a persuasão é 0 efeito das influências das crenças do individuo juntamente com as associações que o mesmo faz com o objeto em consideração. Segundo isto, a persuasão pode salientar crenças já existentes, modificá-las ou criar novas crenças (Leite \& Batista, 2009). 
Segundo as crenças e opiniões preformadas que o ser humano vai integrando ao longo da vida mediante a cultura, tradições, a educação que teve, o seu nível social, académico e profissional e a sua experiência de vida, há informações que aceita melhor pois são com as quais se identifica mais (Kulcinski, 2014).

Mediante estes pilares que constituem o padrão psicológico do individuo, a subjetividade é aproveitada para persuadir apelando à emoção e fazendo uso de premissas que são mais aceites pelo auditório (Kulcinski, 2014).

Pascal (1958) considera que persuadir é uma arte que se baseia em agradar e convencer os homens de tal maneira que estes reagem mais pelo emocional do que pelo racional (as cited in Sénéchal-Machado, 1997).

Para Skinner (1983) persuadir é adoçar. Ao manipular as circunstâncias com estímulos e consequências de reforço positivo, modificamos o que a pessoa vê quando olha (as cited in Sénéchal-Machado, 1997).

Persuadir é influenciar. Efetiva-se por meio de técnicas generalistas de interação social que geram mudanças de opiniões e atitudes no outro. "Modificar opiniões é, basicamente, criar, no outro, emoç̃̃es ainda não existentes, procurando evocar ou estimular as atitudes adequadas a um objetivo específico, atitudes essas que são, usualmente, aprendidas no convívio social" (Parsons, 1963 as cited in Sénéchal-Machado, 1997, p.28).

A comunicação persuasiva é um método leva 0 individuo a crer no que 0 emissor pretende, bem como a assimilar desejos que não são reais e assim ser influenciado na adoção de ideias que são tão fortes que muitas vezes acredita que são de facto suas. É um apelo à emoção, empatia e falácias lógicas (Kulcinski, 2014).

\section{Contexto Histórico da Persuasão}

Nesta seção iremos abordar 0 contexto histórico da persuasão segundo os estudos de Citelli (2002) e Fidalgo (2010) para perceber-se o caminho que a persuasão trilhou até aos dias de hoje.

Quando se fala em persuasão, fala-se em retórica. A preocupação com a arte de falar nasceu entre os gregos, estes apreciavam a eloquência. Quem apresentasse a melhor retórica era o vencedor e tinha mais influência perante a assembleia geral (Sousa, 2001).

Segundo Citelli (2002) preocupavam-se não apenas em falar, mas como fazê-lo de forma elegante e convincente.

0 modelo de comunicação segundo Aristóteles é triangular, compreende o orador, a mensagem e 0 auditório. A retórica mediatizada vem acrescentar mais um componente, os meios (Fidalgo, 2010).

A relação do orador com 0 auditório transforma-se significativamente se for mediatizada, bem como a mensagem consoante o meio que é apresentado (Fidalgo, 2010).

Ao serem introduzidos os meios na comunicação persuasiva, o orador individual foi substituído por entidades coletivas de origem política, organizacional, cultural ou social, ou seja, já não fala por ele próprio, mas em nome de alguém ou algo. Consequentemente 0 discurso oral persuasivo também foi substituído pelo discurso escrito (Fidalgo, 2010).

Desta forma, as agências de comunicação tornaram-se relevantes, pois as organizações precisaram criar a sua própria identidade (a marca, logotipo, publicidade) para que conseguissem cristalizar a sua história através da sua marca e estreitar relações comerciais e de afeto (Fidalgo, 2010).

Outro meio que veio revolucionar a oratória foram as apresentações gráficas, como exemplo da projeção do PowerPoint, sendo que em muitos casos a parte visual torna-se mais importante do que o próprio orador (Fidalgo, 2010).

"O que entra pelos olhos é mais forte do que o que entra pelos ouvidos; somos mais facilmente e mais rapidamente convencidos pelo que vemos do que pelo que ouvimos. Ou seja, de um paradigma oral passa-se a um paradigma visual, muito mais perto da própria realidade e experiência quotidianas (Fidalgo, 2010, p.240).

A retórica mediatizada vem desafiar a retórica clássica através do uso da multimédia. Dá-se a passagem de uma cultura oral para visual (Fidalgo, 2010)

As comunicações públicas atuais, na sua maioria, não são feitas presencialmente. É através dos jornais, rádio, televisão e internet que se debatem e defendem situações públicas e se persuade outros sobre diversas questões (Fidalgo, 2010). 
A persuasão é usada para influenciar as pessoas aos diversos níveis, desde político, social, económico, cultural, científico e religioso, de tal forma que se pode falar em indústrias de persuasão (Fidalgo, 2010).

A industrialização da persuasão teve início no século XX durante a I Guerra Mundial, em que os governos das potências recorriam a estratégias de persuasão para mobilizar as populações a lutarem na guerra, fazendo uso em massa de cartazes e folhetos (Fidalgo, 2010).

Entre as Guerras Mundiais, a persuasão aperfeiçoa-se com o cinema e a rádio, tornando-se uma arma importante na II Guerra Mundial e criando-se marcos na retórica de massas como o cinema de Chaplin e de Eisenstein e a difusão radiofónica dos discursos de Churchill e Goebbels (Fidalgo, 2010).

Com a sociedade industrial surge a sociedade do consumo. Esta sociedade devido à concorrência deparase com uma vasta variedade de produtos e as suas escolhas são feitas por meio da informação e persuasão publicitária.

Tornam-se importantes para a economia de mercado a publicidade, relações públicas e o marketing (Fidalgo, 2010).

"Mudou a sociedade, mudou a cultura, mudou a religião, mudou o modelo de governação política, pelo que a retórica não poderia manter-se inalterada, ela própria tão imbricada com a sociedade e com as formas de vida social e política" (Fidalgo, 2010, p.245).

\section{Da Retórica Clássica à Moderna}

Da retórica clássica até à retórica moderna houve uma evolução na sociedade e pretendemos apresentar este assunto através dos estudos dos autores Citelli (2002) e Mateus (2018).

A persuasão está diretamente ligada ao discurso, pelo que não possível falar da mesma sem falarmos da retórica (Citelli, 2002).

Para Quintiliano (1994), a retórica é a arte de falar bem, com eloquência e capacidade expressiva que visa 0 reconhecimento. Para Aristóteles, as técnicas de persuasão são essenciais, o restante são meros acessórios. Já para Isócrates, 0 importante era o discurso (Mateus, 2018).

Os gregos criaram escolas com disciplinas que ensinassem a arte de dominar a palavra que passava pela eloquência, gramática e retórica (Citelli, 2002).

A retórica preocupava-se essencialmente em embelezar 0 discurso, escolher as palavras que soavam mais bonitas e as expressões mais inusitadas para levar ao convencimento de determinada verdade (Citelli, 2002).

Aristóteles criou a obra "Arte da Retórica", considerada a síntese das visões dos estudos retóricos e que funcionava como um modelo de normas e regras para construção de textos persuasivos. Para este, o objetivo não era dissecar a verdade de algo, mas fazer com que esse algo parecesse verdade. A ética não era tida em conta, 0 importante não é o que se diz, mas como se diz (Citelli, 2002).

"Persuadir falando bem e não tanto falar bem para persuadir." (Mateus, 2018, p.19).

Segundo Citelli (2002), a retórica clássica preocupava-se com o embelezamento do discurso que, muitas vezes, camuflava o vazio de ideias, pelo que com o passar dos séculos houve um vazio na retórica e esta foi alterando as suas funções.

Os trabalhos mais recentes passaram a ter uma nova abordagem da retórica preocupando-se mais com a análise do discurso, das figuras de estilo e das técnicas argumentativas e a sua aplicação foi ampliada até aos filmes, publicidades, vídeos, entre outros. Deu-se a passagem da retórica clássica para a retórica moderna (Citelli, 2002).

Os meios de comunicação massivos, desde a imprensa, rádio, televisão, internet e outros vieram desafiar os oradores. As mensagens persuasivas são muito mais rápidas do que no passado. Um anúncio pode ser partilhado com o mundo em segundos por meio das redes sociais online (Mateus, 2018).

Mateus (2018) considera a retórica como uma atividade persuasiva que visa alterar a forma como a pessoa olha ou age relativo a determinada situação, e que esta pode ser por meio do discurso verbal ou não verbal. Por exemplo, passar o excerto de um filme com apelos visuais para que os telemóveis sejam desligados no cinema, 
é um exercício retórico uma vez que pretende persuadir os espectadores a mudança de comportamento (Mateus, 2018).

0 ato de persuadir tornou-se uma profissão, como exemplo dos publicitários, comerciais, relações públicas, marketing, influencers, youtubers, entre outros (Mateus, 2018).

\section{Publicidade Persuasiva}

Iremos apresentar e exemplificar este assunto tão pertinente à luz de Citelli (2002) de forma a perceber-se como são feitas as campanhas publicitárias e qual 0 impacto que as mesmas têm.

Segundo Citelli (2002), um texto publicitário pode ser feito de duas formas, de forma original e provocadora ou simplesmente fazer uso de estereótipos. Os anúncios que não cumprem as normas predeterminadas pela sociedade causam grande impacto devido à estranheza e incómodo que podem levar à reflexão ou indignação, principalmente quando se tratam de temas considerados tabus como exemplo do homossexualismo. Desta forma, os mesmo tornam-se persuasivos.

É percetível que os anúncios mais arrojados e até inovadores são acompanhados de lugares-comuns, como exemplo de uma publicidade de pasta de dentes ser apresentada por uma pessoa que se pareça dentista, e assim tornar-se persuasivo (Citelli, 2002).

Os textos persuasivos têm origem num conjunto de vários fatores, desde os psicossociais económicos, aos efeitos retóricos que fazem uso de figuras de estilo, técnicas argumentativas e raciocínios (Citelli, 2002).

Citelli (2002) cita um exemplo: "Nove entre dez estrelas do cinema usam Lux" (p.42).

0 slogan tem sete palavras gramaticais e segundo Citelli (2002) para ser considerado um bom slogan 0 mesmo deverá apresentar entre quatro a sete palavras gramaticais.

0 raciocínio deve de ser o mais claro possível, trata-se de um silogismo, que passa por três etapas: a premissa maior, a premissa menor e a conclusão. A premissa maior neste caso específico é "As mais belas mulheres do cinema usam Lux." A premissa menor corresponde a "Você é (ou quer ser) uma bela mulher". E a conclusão passa por "Você deve usar Lux (assim será tão bela como as formosas atrizes)" (Citelli, 2002, p.43).

Neste exemplo, verifica-se também o uso das figuras de estilo comparação e hipérbole. A comparação faz a relação da inalcançável estrela à mulher comum e a hipérbole refere um exagero considerável na parte "nove entre dez, usam Lux!" (Citelli, 2002, p.43).

Este slogan direciona-nos para duas realidades de intensa pressão psicossocial, a exclusão e os símbolos (Citelli, 2002).

A exclusão porque socialmente ninguém pretende ser excluído, ou seja, quem não usa Lux está em companhia de alguém feio, uma vez que o texto persuasivo remete-nos para a beleza (Citelli, 2002).

0 símbolo tem a ver com o que é melhor aceite pela sociedade, ou seja, a importância que se dá aos padrões de beleza e neste caso específico torna-se uma obrigação este convite à beleza (Citelli, 2002).

Brown (1971) afirma que a publicidade faz uso de esquemas básicos para persuadir (as cited in Citelli, 2002). E Citelli (2002) cita cinco desses esquemas básicos para persuadir como o uso dos estereótipos, a substituição de nomes, criação de inimigos, apelo à autoridade e afirmação e repetição.

0 uso dos estereótipos tratam-se de esquemas e fórmulas já reconhecidas. Por exemplo, um indivíduo que apresente uma boa aparência dá-nos uma ideia de honestidade, logo é um bom modelo a ser seguido. A característica principal do estereótipo é que a mesma é tida como uma verdade absoluta (Citelli, 2002).

Na substituição de nome, de forma a influenciar certas situações efetua-se a alteração dos termos para soar melhor (Citelli, 2002).

Na criação de inimigos há a criação de inimigos imagináveis no discurso persuasivo (Citelli, 2002).

No apelo à autoridade procura-se colocar alguém na publicidade que valide o que se pretende afirmar, como exemplo temos as citações que são feitas em dissertações de mestrado para tornarem 0 artigo credível (Citelli, 2002).

A afirmação e repetição são importantes uma vez que a afirmação pode gerar dúvidas, mas a repetição cria 


\section{PUBLICIDADE PERSUASIVA. REVISÃO BIBLIOGRÁFICA}

uma possível aceitação. Um exemplo citado por Citelli (2002) foi que o teórico Goebbels, da propaganda nazista, afirmava que uma mentira repetida várias vezes torna-se mais credível do que uma verdade dita apenas uma vez.

\section{Causas Psicossociológicas da Publicidade}

De forma a explicar as causas psicossociológicas da publicidade contemporânea, Mateus (2011) apresenta o conformismo e a imitação social.

Considera que 0 individuo quando está na presença de alguém é socialmente influenciado, modificando 0 seu comportamento de forma efetiva ou imaginável. Isto acontece devido ao medo que 0 ser humano tem de se isolar, de não se sentir incluído e reconhecido no ambiente em que está inserido (Mateus, 2011).

Existem fatores que reforçam o conformismo: a importância numérica da maioria, unanimidade da maioria, prestígio ou autoridade pessoais. E o conformismo presente na publicidade frequentemente é uma norma (Mateus, 2011).

A imitação social surge para se entender como a adesão ao conformismo é tão significativa. Pertencemos a uma sociedade porque partilhamos condutas semelhantes sendo influenciadas pela mesma e 0 ser humano tem tendência para imitar, sendo uma característica inata (Mateus, 2011).

A imitação e o conformismo são mais atitudes do inconsciente do que atos intencionais (Mateus, 2011).

\section{CONCLUSÃO}

Em jeito de resumo, importa realçar que Persuadir é influenciar, levar uma pessoa a crer em algo através do discurso e também dos meios disponíveis. E para se persuadir faz-se uso da retórica, a arte de falar.

Os gregos foram os primeiros a darem relevância à retórica de uma maneira muito peculiar, não era apenas importante 0 que se dizia, mas como se dizia, como se colocavam as palavras. Preocupavam-se em enfeitar 0 discurso de forma a que o mesmo fosse convincente. Não era necessário ter apenas um bom discurso, mas fazêlo de forma elegante.

Mais tarde veio Aristóteles com a sua obra trazer novas luzes a este tema da retórica, trazendo um modelo de comunicação que se baseava no orador, na mensagem e no auditório.

Com o avançar do tempo surgiram os meios, tornando assim a retórica mediatizada. Começou-se a fazer uso dos meios como auxiliares da retórica, desde os jornais, a rádio, a televisão e a internet, e desta forma passouse de uma cultura oral para uma cultura visual.

A sociedade atualizou-se com o desenvolvimento de novos meios, percebeu-se também que o discurso era na maioria das vezes camuflado pela sofisticação das palavras, pelo que deixou de ter lugar a retórica clássica e veio imperar a retórica moderna.

A retórica moderna ocupou-se com a análise dos discursos, das figuras de estilo e das técnicas argumentativas e é atualmente aplicada em publicidades por meio de radio, televisão ou internet, vídeos que circulam nas redes sociais, em filmes, entre outros.

Os meios de comunicação em massa surgiram como um desafio aos oradores porque através destes as mensagens chegam muito mais rápido ao recetor do que antigamente, a propagação da informação é imediata.

Hoje em dia há diversas profissões que fazem uso da persuasão, como relações públicas, publicidade e marketing, influencers, youtubers, entre outros.

A publicidade persuasiva faz 0 uso de figuras de estilo, técnicas argumentativas e raciocínios, para atingir 0 fim a que se propõe, que é persuadir algo, desde apelar à emoção na compra de um produto, à passagem de uma informação importante ou influenciar a adotar certos comportamentos.

Essas estratégias aplicadas em publicidade são capazes de romper com estereótipos e tornar um anúncio excecionalmente memorável.

No entanto, a persuasão está limitada aos conhecimentos que a pessoa já tem sobre o que se está a apresentar, podendo criar novas crenças, modificar ou salientar crenças já existentes. Assim, mediante a cultura, a 
educação, o nível social e as experiências de vida do individuo a publicidade persuasiva faz uso de premissas que podem ser melhor aceites.

As causas psicossociológicas da publicidade persuasiva da atualidade são explicadas por meio do conformismo e da imitação social, em que o ser humano tende a imitar o outro numa sociedade de forma inconsciente, devido ao facto de partilhar os mesmo costumes e a mesma cultura.

A psicossociologia da comunicação tem neste tema um papel fundamental e enquanto psicólogos devemos ter atenção ao estudo dos comportamentos e dos atos comunicativos como forma de compreender as massas e assim influenciá-las de forma conscienciosa, respeitadora, assertiva e em prol do bem comum, em primeira instância pelo bem supremo de cada um de nós!

\section{REFERÊNCIAS BIBLIOGRÁFICAS}

Citelli, A. (2002). Linguagem e Persuasão. São Paulo: Editora Ática. Retrieved from https://edisciplinas.usp.br/pluginfile.php/4234777/mod_resource/content/1/Livro\%20Citelli.pdf

Fidaldo, A. (2010). Da retórica às Indústrias da Persuasão. Imprensa da Universidade de Coimbra. D0l:http://dx.doi.org/10.14195/978-989-26-0498-5_14

Kulcinski, A. (2014). Técnicas de Persuasão. Dissertação de Mestrado em Ciências da Comunicação: Universidade Nova de Lisboa. Retrieved from https://run.unl.pt/bitstream/10362/ 14785/1/Arcadiy\%20Kulchinskiy\%20-\%20T\%C3\%A9cnicas\%20da\%20Persuas\%C3\%A30.pdf

Leite, F., \& Batista, L. L. (2009). A persuasão, os Estereótipos e os Impactos da Propaganda Contraintuitiva. Contemporânea, Rev. De Comunicação e Cultura, 7(1), 1-24. D0I: http://dx.doi.org/10.9771/1809-9386contemporanea.v7i1.3603

Mateus, S. (2011). Publicidade e Consumação nas Sociedades Contemporâneas. Covilhã: LabCom Books. Retrieved from http://www.labcom-ifp.ubi.pt/ficheiros/20110505-samuel_mateus_a_figuracao.pdf

Mateus, S. (2018). Introdução à Retórica no Séc. XXI. Covilhã: Editora LabCom. Retrieved from http://www.labcom-ifp.ubi.pt/ficheiros/201804271553-201807_introretorica_smateus.pdf

Sénéchal-Machado, A. M. L. (1997). 0 Processo de Persuasão e o Comportamento de Persuadir. Psicologia Ciência e Profissão, 17(3),28-34. Retrieved from http://www.scielo.br/pdf/pcp/v17n3/05.pdf

Sousa, A. (2001). A Persuasão. Covilhã: Serviços Gráficos da Universidade da Beira Interior. Retrieved from http://www.labcom-ifp.ubi.pt/ficheiros/20110826-sousa_americo_persuasao.pdf 
